\title{
Space Shuttle Abort Evolution
}

Edward M. Henderson ${ }^{1}$ and Tri X. Nguyen ${ }^{2}$

NASA, Johnson Space Center, Houston, Texas 77058

\begin{abstract}
This paper documents some of the evolutionary steps in developing a rigorous Space Shuttle launch abort capability. The paper addresses the abort strategy during the design and development and how it evolved during Shuttle flight operations. The Space Shuttle Program made numerous adjustments in both the flight hardware and software as the knowledge of the actual flight environment grew. When failures occurred, corrections and improvements were made to avoid a reoccurrence and to provide added capability for crew survival. Finally some lessons learned are summarized for future human launch vehicle designers to consider.
\end{abstract}

\section{Nomenclature}

$\begin{array}{ll}\text { AOA } & =\text { Abort Once Around } \\ \text { ATO } & =\text { Abort to Orbit } \\ \text { ET } & =\text { External Tank } \\ \text { FSW } & =\text { Flight software } \\ \text { ISS } & =\text { International Space Station } \\ \text { MECO } & =\text { Main Engine cutoff } \\ \text { OFT } & =\text { Orbiter Flight Test Program } \\ \text { OMS } & =\text { Orbiter Maneuvering System } \\ \text { RCS } & =\text { Reaction Control System } \\ \text { RTLS } & =\text { Return to the Landing Site } \\ \text { SOFT } & =\text { Suborbital Flight Test Flight } \\ \text { SSME } & =\text { Space Shuttle Main Engine } \\ \text { TAL } & =\text { Transoceanic Abort Landing } \\ \text { TPS } & =\text { Thermal Protection System } \\ \text { TVC } & =\text { Thrust vector control } \\ \text { WTR } & =\text { Western Test Range }\end{array}$

\section{Introduction}

$\mathrm{T}$ The Space Shuttle was intended to be a reusable launch vehicle. However the national budget could not support that large of an initial investment required for the design and development of a fully recoverable and reusable vehicle. Therefore a compromise design (Fig. 1.) was selected with an expendable external propellant tank that lowered development cost and corresponding increase in the operations cost. The Orbiter was designed for up to 100 flights and a 10 year life; the Solid Rocket Boosters and Motors were recovered after every launch and refurbished

\footnotetext{
${ }^{1}$ NASA/JSC Space Shuttle Program, Advanced Studies and AIAA Associate Fellow
}

${ }^{2}$ NASA/JSC Space Shuttle Program, Advanced Studies and AIAA Associate Fellow 
for a future flight. The External Tank (ET) was expendable and a new one built and flown on each flight. Space Shuttle Main Engines (SSME's) were extensively checked and test fired before being reused. This resulted in approximately the same cost over the twenty-five year operating life but with a level and more affordable annual budget. With this framework, added frills for enhanced abort features were not affordable during the initial design. The intent was to design a robust and reliable vehicle that could accommodate a safe return with the loss of a single main engine. Two crew ejection seats were provided during the Orbital Flight Test program to protect for design surprises (infant mortality). Aborts resulting from other or additional failures would require the flight crew or ground assist to return the crew and vehicle. This required many hours of training for both the crew and ground controllers to expedite these aborts successfully. The safe recovery of the crew was based on training that used the inherent capabilities of the Space Shuttle. Once the ejection seats were no longer available and as the mission requirements increased, added abort capability was needed and had to evolve during shuttle operations.

This paper addresses some of the key abort improvements that have been made over the life of the Space Shuttle program that have improved crew safety and reduced risks. Beyond the designed margins of safety and redundancy, the hardware and flight software have been modified with the increasing challenges for the existing Space Shuttle vehicle (Ref \#1). As the performance grew so did the entry and landing weights, requiring structural beef up and software changes to stay within specified design limits (Ref \#3). These were needed to carry larger payloads, increases in orbital inclination and altitude, large assembly tasks and to fly longer missions. Additional contingency sites were added to support changing ground tracts increasing available emergency runways. Most required flight software changes for additional targets and supporting navigational aids. As flight risks were identified and better understood improvements were made to mitigate the risk, the largest were those following the Challenger accident. In addition, all Shuttle abort work was coordinated with the Eastern Range Safety Offices at Patrick AFB.

Finally lessons learned are summarized that should help future human spaceflight and launch vehicle designs. Most importantly is automating aborts wherever possible and verifying the flight software and flight sequences for all planned flight environments (Ref \#2) including the aborts. The abort design is never complete, one should always monitor the flights and identify ways to improve the abort capability and maximize crew safety. 


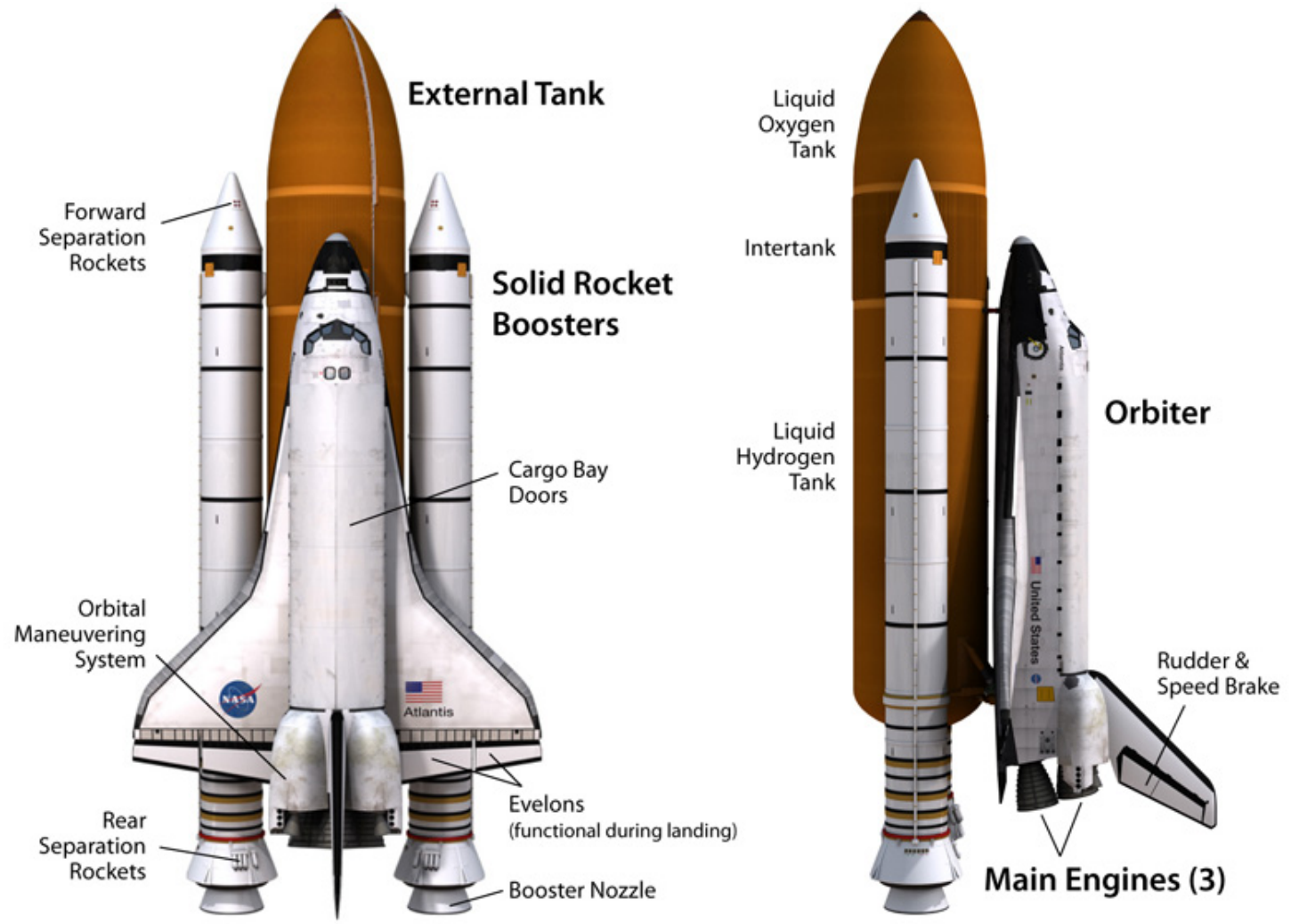

Figure 1. Space Shuttle

\section{Abort Design Philosophy}

The design philosophy for the Space Shuttle was added robustness, with a 1.4 factor of safety, and sufficient flight hardware and software redundancy to minimize the need for aborts. Also crew ejection seats and a backup flight computer and software were added to cover major design flaws and infant mortality concerns. Selected flight design missions were developed to bound the flight conditions and define the environments that the Space Shuttle was expected to operate in for the Shuttle design and development. Four reference missions were defined: two launched from the east coast, a due east launch for maximum performance and a high inclination flight for a possible space station orbit, and two from the west coast, both polar orbit military missions. The latter two military missions required a high cross range and auto land capability.

A crew return capability following the loss of one of the Shuttle main engines was a design requirement. Other design requirements for added cross range, auto land and SSME throttle up capability provided margin for abort use and uncertainties. Contingencies resulting from the loss of additional main engines or unexpected failures were covered by exhausted crew training, crew procedures and mission rules. Onboard computer limitations required most of the abort determination be performed on the ground in the Mission Control Center (MCC). The flight control team and the flight crew trained together during integrated simulations for every Shuttle flight. The teams become proficient in failure recognition and abort execution. These simulations and Shuttle avionics integration 
testing added confidence that the flight software worked and interfaced with the flight hardware for each mission configuration.

The intact aborts following the loss of a single engine were an automated design feature; while the contingency aborts, for all other failures, were mostly flown manually by the crew with ground assistance. The recovery and a safe return for the contingency aborts were developed using the inherent capabilities of the Shuttle vehicle and not always certified. Flight software was added to allow proper sequencing through the necessary flight phase modespowered flight, separation and entry; but the structure and flight control capabilities could not be certified for all the possible abort scenarios. Continued analysis throughout the life of the program significantly improved the certification for the more likely abort cases. These studies supported some hardware modifications and regular flight software improvements were made for increased crew safety.

\section{Launch Abort Modes}

The original ascent design for the Shuttle was to shape the launch trajectory such a continuous abort capability existed for the loss of a main engine from liftoff to the planned main engine cutoff (MECO). A return to the landing site (RTLS) abort capability would exist up until an abort once around (AOA) capability was achieved. The first Shuttle launch was the only Shuttle launch that was flown with this abort shaping. Shaping the ascent to force the RTLS and AOA aborts together was a significant launch performance penalty, approximately $6000 \mathrm{lbs}$. Therefore subsequent Shuttle launches were shaped for maximum payload to orbit. This nominal shaping opened up an abort capability gap between the last RTLS and earliest AOA. A down range abort, trans-ocean abort landing (TAL), was added to fill the gap. Because this was an added capability after the Shuttle was designed it was called a contingency abort until it was certified later in the program.

The intact abort modes are summarized on fig. 2 - 4 and the coverage on fig. 5: 


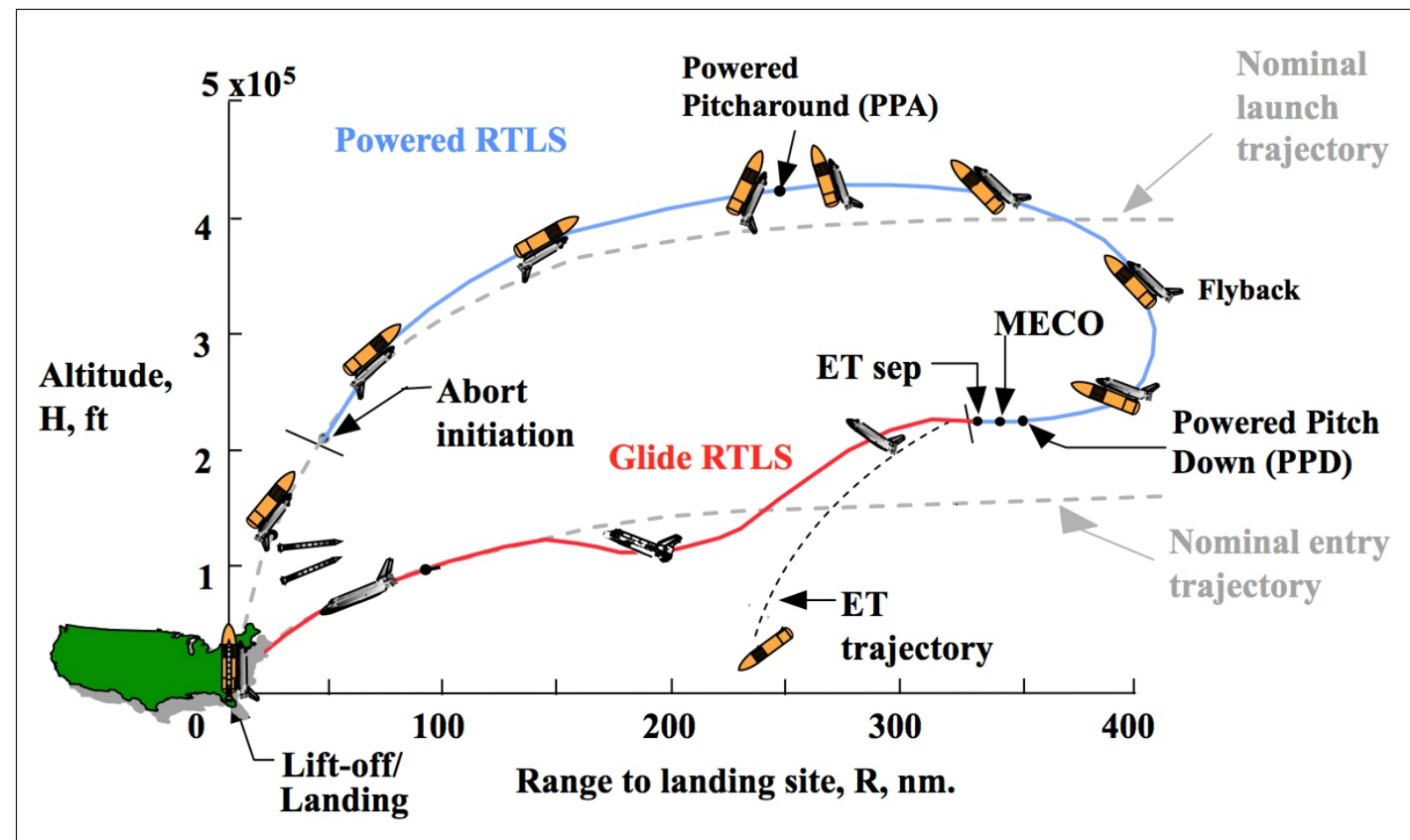

Figure 2. Shuttle Intact Aborts: Return to Launch Site (RTLS) Profile

A. The RTLS has the most differences from the normal Shuttle profiles flown each mission. First because it returns the Shuttle's Orbiter to the KSC landing site, it requires a powered flight pitch around maneuver to kill off the down range velocity and add sufficient velocity for the Orbiter to glide back to the Cape. This maneuver provides a gross control for using up the propellant in the ET, SSME throttling is the fine control necessary to deplete the propellant prior to separating the ET (less than $2 \%$ required for separation). This separation is the most critical maneuver for the RTLS (highest risk) because it is significantly different than the normal ET separation. After the powered pitch down maneuver and MECO, it requires an assist from both the RCS jets and from the aerodynamics to achieve a safe separation. To establish the correct velocity for the Orbiter's return and meet the tight dynamic pressure constraints for separation the altitude has to be high enough causing it to be considerably off the desired equilibrium glide slope for a normal descent. This means the Orbiter is failing in like a rock and a 50 degree angle of attack (the highest required in the program) is needed to avoid breaking the wings off and sufficient control margin to capture the normal entry trajectory without an excessive phugoid during pullout. Once on the normal glide slope the return is much like the normal entry.

B. TAL aborts are much closer to the normal Shuttle flight profiles and once it was certified it was preferred to RTLS when an overlap occurred. These aborts were far enough down range that near normal ET separation and entry could be performed. The largest concern was with the ET rupturing close to the Orbiter during the descent. Surprisingly the ET had a more violent rupture than anticipated resulting in a fairly large 
envelope of debris the Orbiter had to avoid to make a safe entry. Two things were required to provide sufficient separation distance between the ET and Orbiter prior to rupture: first rolling the Shuttle during ascent to condition the ET thermally to delay rupture and second was to adjust the TAL MECO target conditions to achieve an adequate separation distance between the vehicles (this sometimes required delaying the earliest TAL). Another difference was because the TAL sites were selected primarily for location to the ascent ground track, they didn't have as long of a runway or the navigation aids desired for landing. To compensate for these deficiencies runway barriers were later added and additional NAV aids and ground support were provided for the specific missions.

C. The AOA is the least likely abort mode because the improvements in the abort to orbit (ATO) with deorbiting opportunities early in the flight have about the same capability as the AOA except for when the performance is below normal on the earliest abort times. A time critical contingency abort would be a more likely requirement for $\mathrm{AOA}$.

D. The ATO is the preferred abort option whenever that capability exists. It continues the ascent with the two remaining SSME's and inserts in a safe orbit giving time to assess the situation and schedule a normal return to a primary landing site or continue the planned mission. This was the only intact abort performed in the program on STS-51F following an erroneous engine shutdown from a faulty sensor reading. There is a press to MECO (PTM) abort mode which can occur late enough in the launch to continue the normal mission with no degradation.

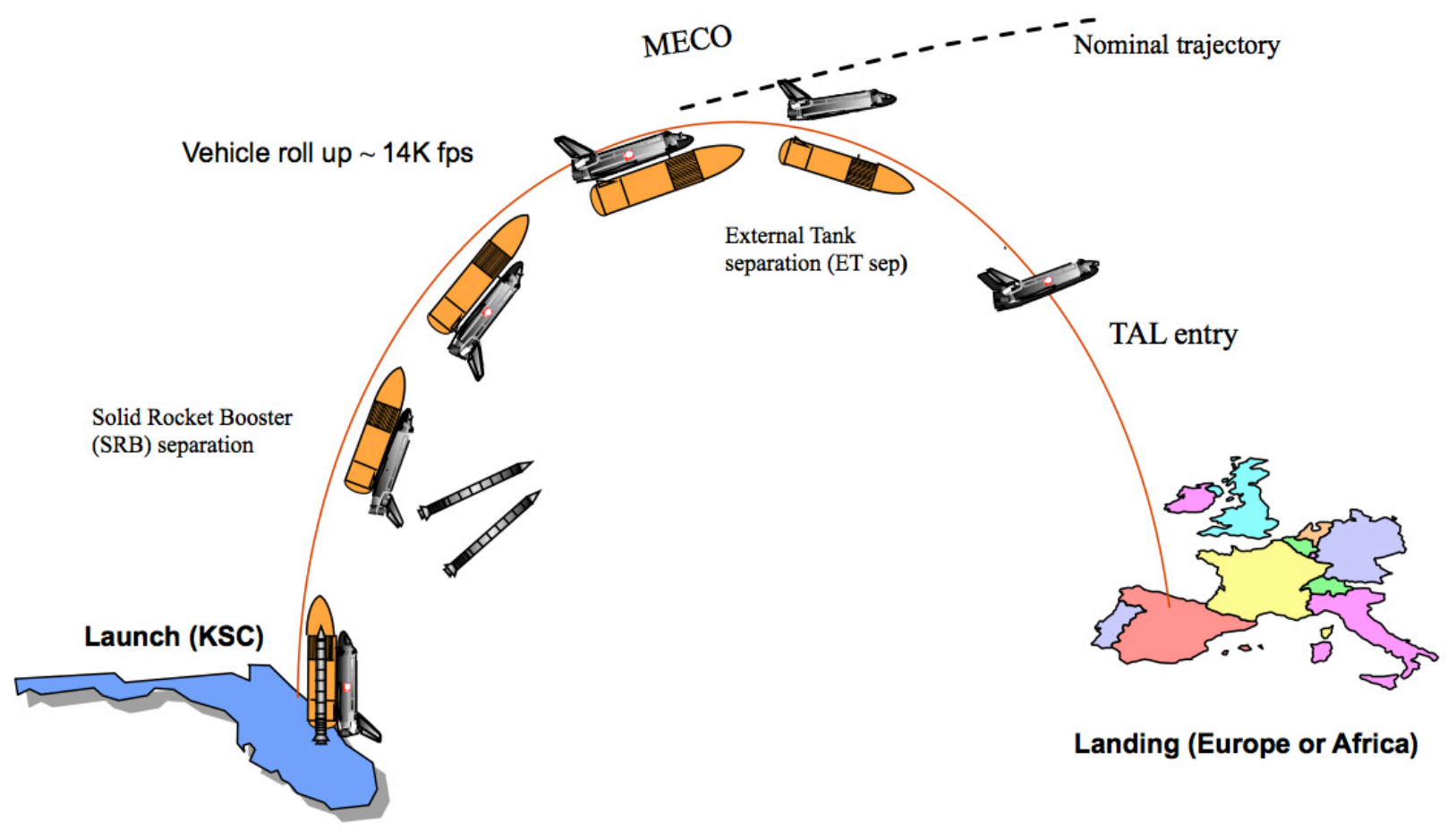


Figure 3. Shuttle Intact Aborts: Transoceanic Abort Landing (TAL) Profile

AOA Profile

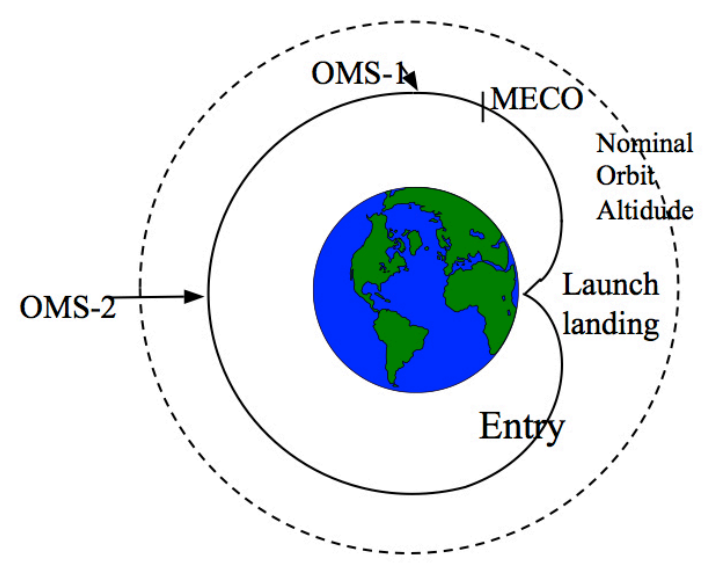

\section{ATO Profile}

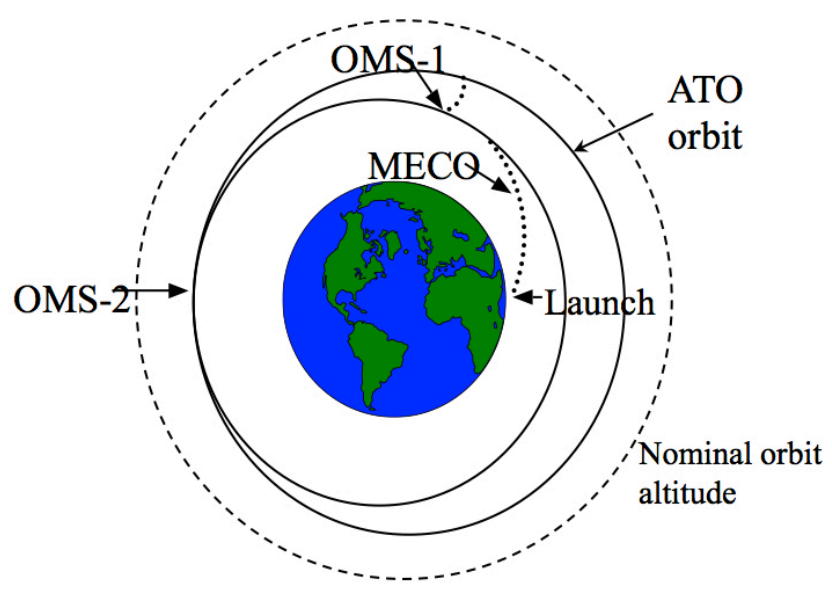

- Orbital Maneuvering System (OMS)-1 burn to raise altitude to acceptable post-MECO apogee (Performance-related AOA only).

- OMS-2 burn to deorbit

Figure 4. Shuttle Intact Aborts: Transoceanic Abort Landing (TAL) Profile

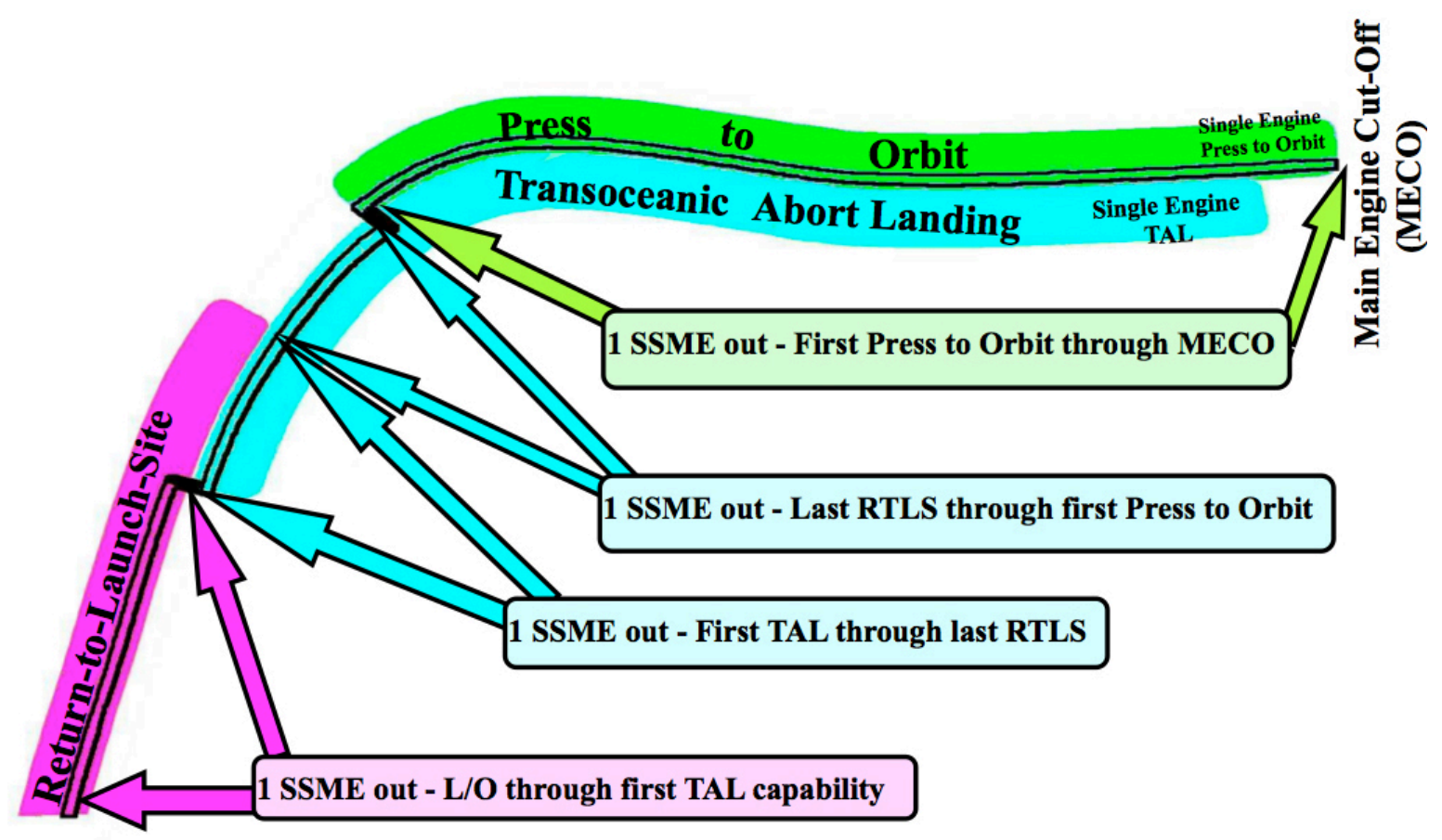

\section{Liftoff}

Figure 5. Shuttle Ascent Abort Profile 


\section{Major Program Milestones}

There have been major milestones, planned and unplanned, in the life of the shuttle program that provided opportunities or mandated abort improvements. The following discusses some of the more prominent events:

\section{A. Pre-Shuttle Launch}

Prior to launching the Space Shuttle's Orbiter vehicle into space an ALT program was conducted, separating the Enterprise off the 747 and landing the Orbiter on a runway at the EAFB to insure the Orbiter could land safely. A surprise happened during the transfer of Columbia from the builder on the west coast to the launch site at KSC, many of the Orbiter thermal protection ceramic tiles fell off during the ferry flight. This raised a major concern- should the TPS tiles fall off during launch the Orbiter would not be able to survive the heat of entry. Actions were taken to review and improve the tile bonding process. A backup plan was to change the first Shuttle flight to a suborbital flight test (SOFT) in case tiles fell off during the first stage the Orbiter could return without being thermally stressed. Finally improvements in tile attachment and extensive testing provided the confidence to proceed with the planned launches without a suborbital flight.

\section{B. Orbital Flight Test Program}

The Orbital Flight Test (OFT) Program was the initial checkout phase for Shuttle launches. Conservatism and data collection were the key objectives for the first four flights. As mentioned earlier, crew ejection seats for the first four flights added a crew escape capability for surprises or an unexpected design flaw. The OFT program provided sufficient flight information to verify the models used to conduct a commit-to-flight activity prior to each launch and to refine the crew procedures and mission rules needed for operations. It also provided the confidence to disable the crew ejection seats (later to be removed) and add additional crew members.

\section{Shuttle Operations}

Shuttle operations were where improvements started in earnest. First major mods to the FSW were initiated to support the expanded mission requirements and to add and improve on the basic capabilities used to support the test program. Software updates were routinely scheduled through a FSW control board and updated on a priority need and available skills. All updates were verified, tested and used in the flight design prior to each mission. Changes were needed early on for additional performance to meet increasing payload demands. As payload weights increased the abort landing weights rapidly exceeded the design requirements. To reduce the landing weights software sequencing logic was added to dump residual fluids/propellants during the abort that had not been used because of the early termination. These dumps were normally during the abort after MECO and sometimes during entry were not standard ops for the propellant tanks, feed lines, etc. Therefore dumps 
could only be performed during limited orientations and gravity loads and not all fluids could be expelled. All requiring added certification and testing.

The next change was going to a higher inclination ( $\mathrm{i}=57 \mathrm{deg}$.) on STS-9. This change resulted in a new ground track and over flight during ascent requiring new northerly abort landing sites for TAL (Fig. 6). It also introduced additional contingency abort landing sites along the East coast that could improve the chances for a landing on a runway for certain failures that would have been water ditches for the more easterly launches previously flown. This was followed by the deletion of the OMS-1 maneuver on STS-11, going from a standard insertion to a direct insertion. The change saved OMS propellant, which was critical for that mission but moved the normal ET impact zone from the Indian to the Pacific Ocean. The OMS burn deletion required a higher MECO velocity increasing the ATO likelihood for an abort over an AOA.

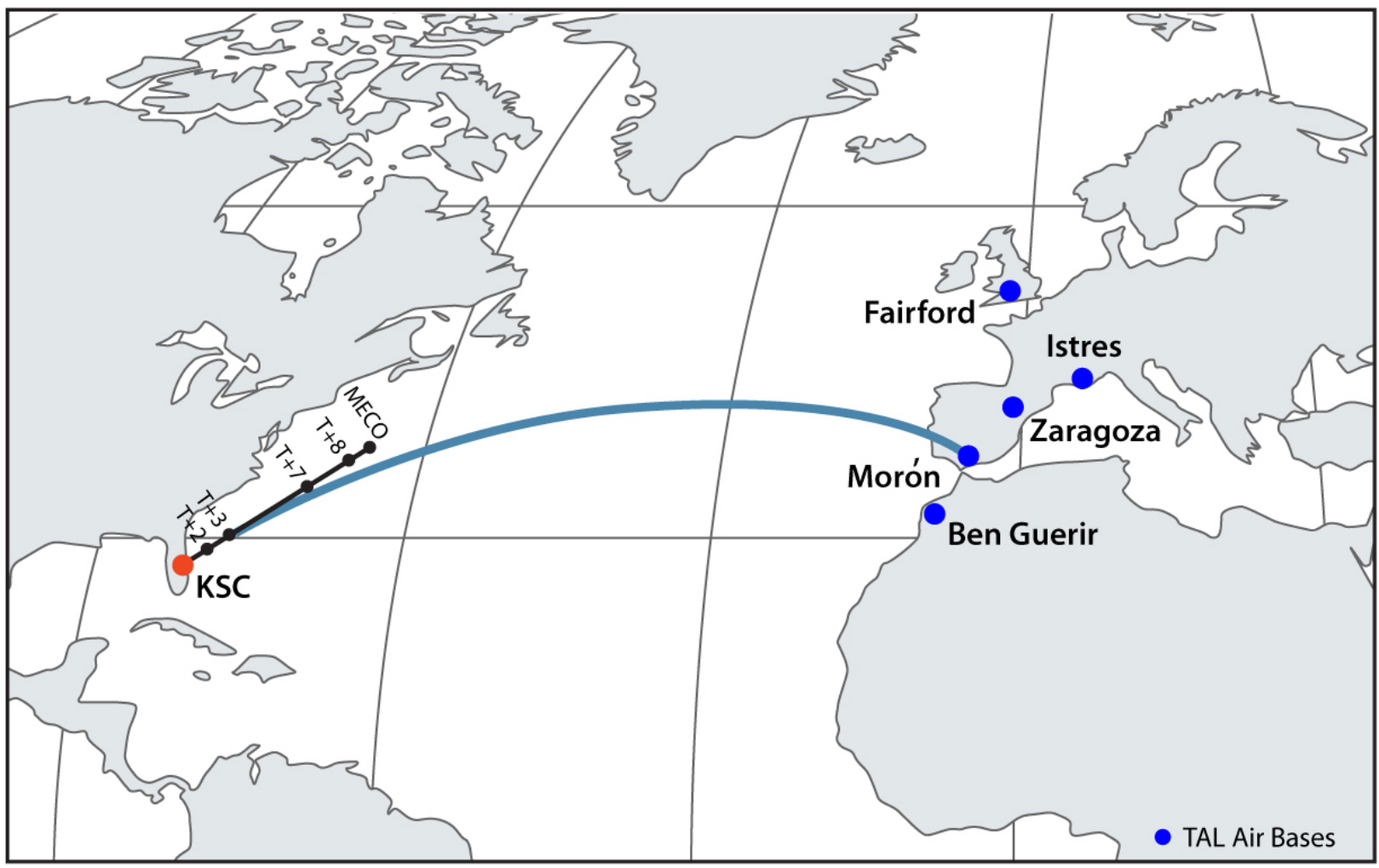

Figure 6. Transoceanic Abort Landing (TAL)

A major design activity was conducted preparing for Shuttle launches on the West coast from Vandenberg AEB. Though not flown due to new program directions following the Challenger accident, a lot of design work and analysis was done. The launch abort environments were significantly different than those for the East coast launches and required a lot of changes for the aborts. Therefore the launch aborts for the initial WTR launch were designed to be benign with considerable margin. Instead of returning to the runway at Vandenberg AFB, the RTLS was designed to return to Edwards AFB where the lakebed offered multiple runway choices for 
surprises. This introduced a problem with an unacceptable ET disposal on land following MECO. A dogleg trajectory was inserted to steer the ET out in the Pacific Ocean prior to MECO to avoid disposal on a populated area. Then bank the Orbiter to glide in to EAFB. It also required adding a more up range TAL site (Easter Island) to avoid an abort gap. A major complication for the planned WTR launches was carrying the Centaur upper stage and its propellant in the Shuttle cargo bay. These required adding and certifying a new propellant dump system to dump these propellants prior to landing for the aborts. Though these WTR missions were never flown the analysis performed added greatly to the knowledge base and was very helpful in follow on Shuttle work.

\section{Challenger $(51 \mathrm{~L})$}

The one event that had the most impact on abort changes was the return-to-flight work following the Challenger accident on STS-51L. Three significant areas were addressed: 1). Develop a bailout capability, 2). Certify the intact aborts and 3). Eliminate the black zones (the loss of crew following a second main engine failure). Lots of other changes happened also but the paper will address these three.

Several design changes were added to support crew bailout. First the hatch was redesigned to facilitate easy and fast egress for the total crew. A pole was added for the crew to slide out on to clear any recontact with the Orbiter. Changes were made to the flight suit that protected for decompression in case of an abort. These features added a capability for the crew to bailout during a stable glide over trying to survive ditching the Orbiter in the Ocean.

As mentioned earlier intact aborts following the loss of a single main engine was a certified design requirement for the Shuttle. However the TAL aborts were added after the design phase and were not fully certified. Prior to returning the Shuttle to flight after the accident the TAL aborts were fully certified and acceptable runways and navigation aids were provided. Once certified and had a profile similar to normal Shuttle separation and descent, TAL aborts became preferable over the RTLS abort for non-time critical aborts.

Also mentioned earlier that not a lot of work was done on contingency aborts - failures beyond the loss of one main engine. The Shuttle aborts are defined as the vehicle has a problem with Space Shuttle Main Engine (SSME) or the critical subsystems/systems that require to abort its mission. Depending on a level of survivability of the crew and vehicle, three zones (green, yellow, and black) for the abort are developed. The green zone is defined as the vehicle and crew is completely recoverable (reach to a landing site). The yellow zone is defined as the crew may be bailed out from Orbiter. A black zone is defined as a vehicle loss of control/ structural failure that could lead to non-recovery or an uncontrollable vehicle and a death of its crew.

The abort with 1 SSME-out is an intact abort that is referred as a green zone for the ascent phase. The abort with 2 or 3 SSME-out is referred as contingency abort (Ref \#4). The contingency abort may be in green, yellow, 
or black zone. Prior to the challenge accident (STS-51L), most of the black zone occurred for 2 or 3 SSME's out during ascent phase.

Key philosophies to minimize the black zone are to detect a failure as soon as possible and train a crew to fly critical maneuvers to control vehicle including a quick separation of the Orbiter from the stack. Shuttle engineers used engineering tools to develop manual crew procedures and flight software to minimize the black zones. Then, both crew and engineers used the Shuttle Engineering Simulation (SES) to validate crew procedures for 2 or 3 engine-out scenarios before they were implemented into the Space Shuttle missions. In addition, the engineers also developed tools to be used by the flight controller to evaluate abort options and predict a vehicle ground impact point. Both crew and flight controllers were trained how to identify off-normal operational situation of the Shuttle systems and select appropriate procedures to fly vehicle to a landing site or control vehicle in the stable condition so the crew can bail out.

The key flight software packages were developed and implemented after 51L to reduce black zone are:

1. The second SSME-out recognition flight software

2. The Automation of the NZ hold phase during the Entry phase, abort propellant dump logic, and Transoceanic Abort Landing (TAL) droop logic

3. The expansion of a landing site table in the flight software to cover additional east-coast landing sites.

Below ( figs. $7 \& 8$ ) are a black zone comparison of the contingency abort capability between pre sts-51L (1986) and post 2000.

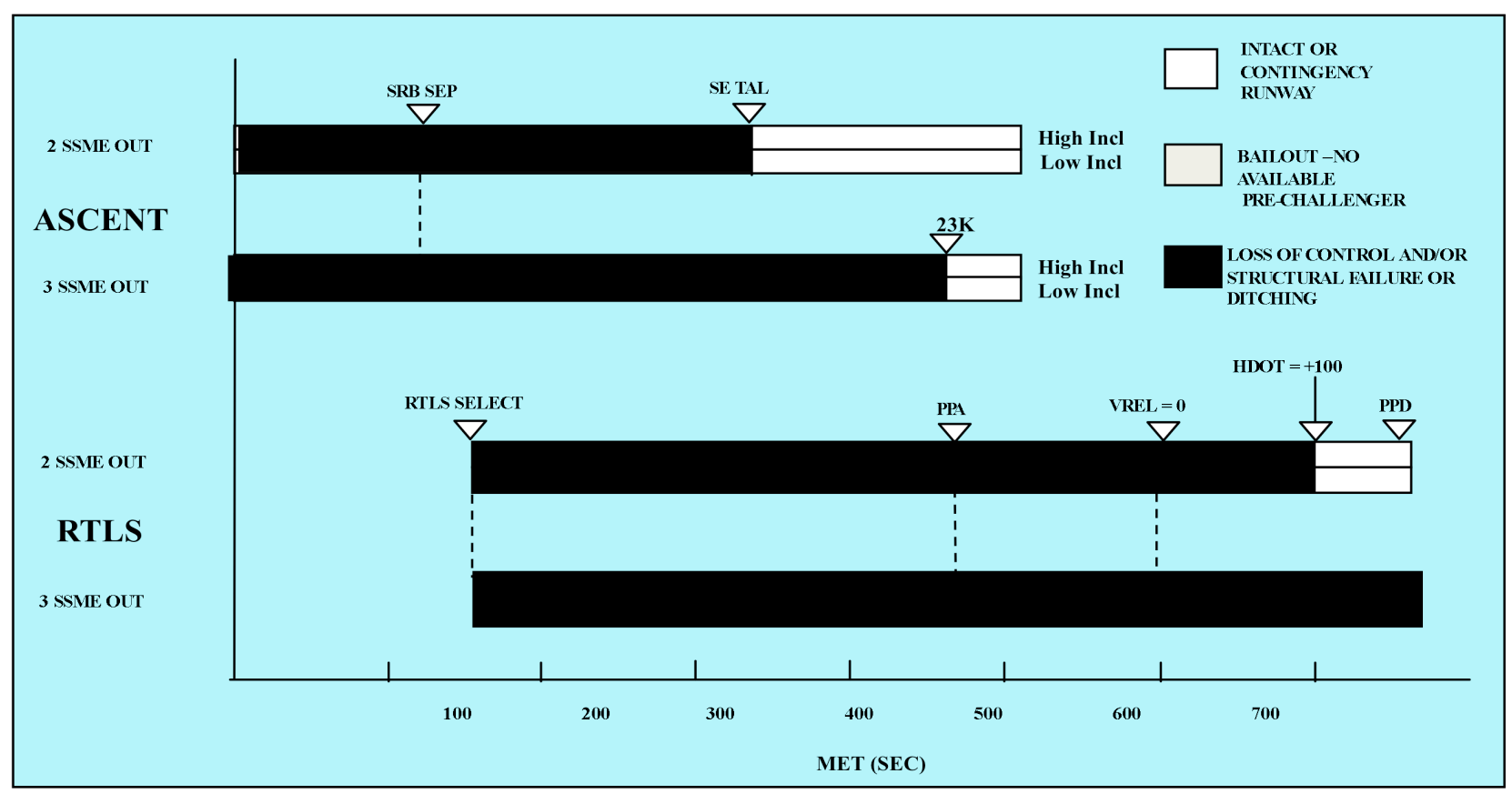

Figure 7. Contingency Abort Capability - Pre STS- 51L (1986) 


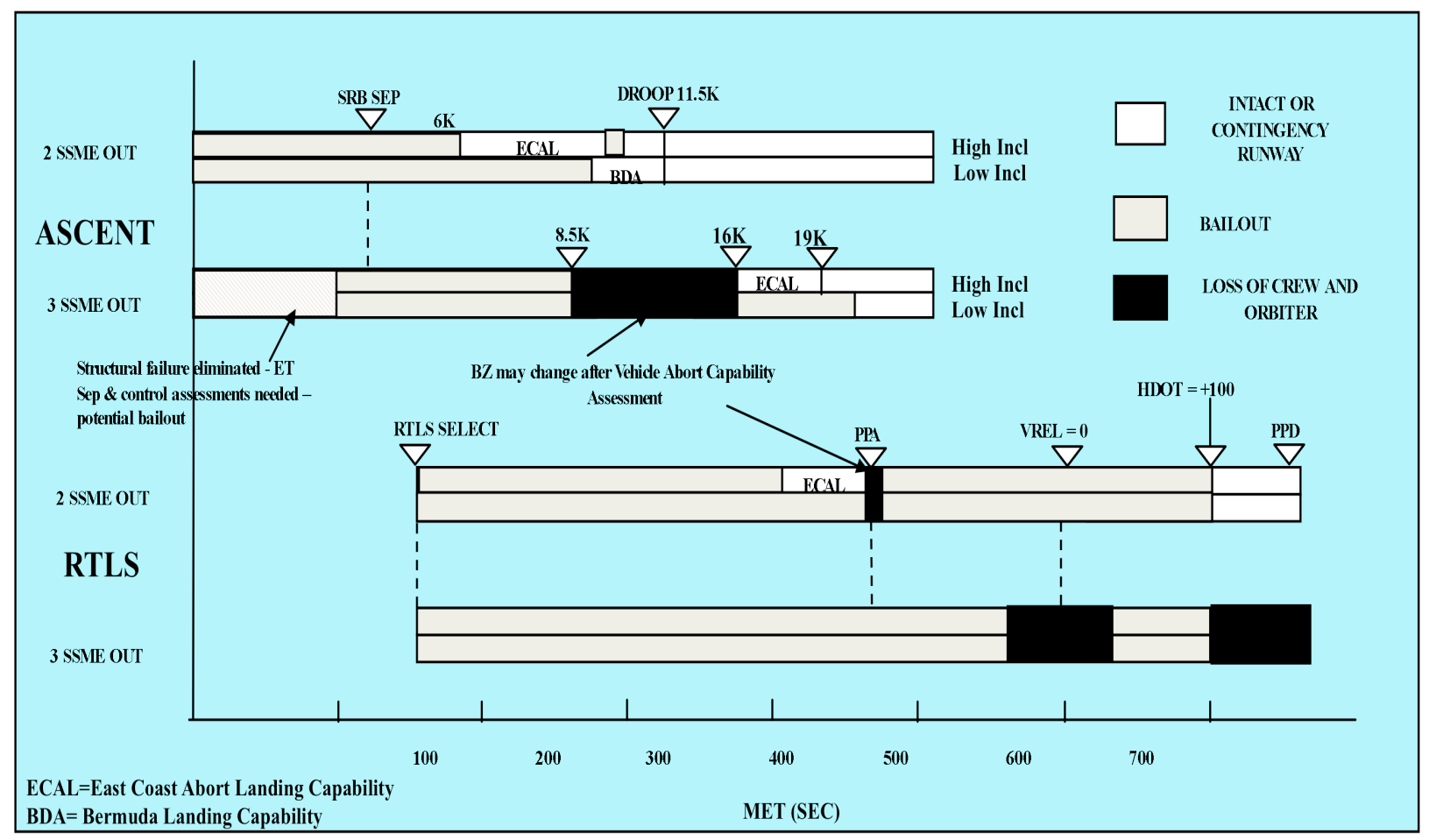

Figure 8. Contingency Abort Capability - Post 2000

\section{E. Shuttle Upgrades}

After the return-to-flight and Shuttle operations were progressing reasonably well, Shuttle upgrades were reconsidered. The plan was twofold, first was to improve the Shuttles operating efficiency and flight rates to significant reduce the operating cost and second to add safety improvements to raise the Shuttle reliability. The goal was to extend Shuttle to 2020 or beyond but due to budget pressures the operations efficiencies were the first to go- not being mandatory and we could fly without them. Work on the safety improvements went along a while longer. The program considered some significant improvements including an advance cockpit for added situation awareness, a new TVC system for the SRB's, advanced SSME health management, a new more sustainable fuel cell, new landing gear and tires were the major ones. Though most of these upgrades were developed, all but a couple were canceled once the decision to retire the Space Shuttle was made. The first phase of the SSME health management, to shutdown an SSME if it exceeded a engine vibration constraint and the new tire were implemented.

The SSME with high throttle was also certified to minimize the exposure for RTLS and TAL aborts. Particularly, the SSP also implemented the RTLS ET/Orbiter separation software change to reducing a risk of loss of control and Orbiter/ET recontact. 
F. International Space Station

Once the assembly for the International Space Station (ISS) was initiated additional Shuttle payload weight was required to launch the larger ISS elements. This increased the abort weights beyond the certification limits for the RTLS separation and entry. New MECO targets and descent profiles were developed and certified. Now with assembling the ISS being the primary task, improvements in the automatic rendezvous and docking were key. Also with the many EVA's required for assembly many crew safety features were added like eliminating share edges that could damage space suits and gloves during space walks. Drag on cables were used to provide extra power to the Shuttle for extending ISS stay times to accomplish more tasks while the Shuttle was docked to the ISS. Once the ISS was manned and could support a large crew the station became a safe haven for the crew if an Orbiter became damaged and not safe for entry.

\section{G. Columbia (STS-107)}

The Columbia accident on STS-107 was probably the deciding factor for the Shuttle termination. The major finding from the accident review board was to understand and eliminate the source of debris during Shuttle ascents. Added modifications and inspections during the ET build process and during the launch was the major focus which added additional cost. Inspections to the Orbiter after launch, at the ISS and prior to entry were added to avoid an unsafe return. As mentioned above, provisions for the ISS to provide a safe haven for the crew were added as well as adding a rescue Shuttle on standby if needed. 


\section{Lessons Learned}

Many lessons can be learned from the development and evolution of the aborts during the Space Shuttle Program:

1. Include aborts as part of the launch/crew vehicle design and development

2. Identify and protect for the likely failure modes

3. Know the vehicle limitations and add design margin

4. Keep abort paths close to normal flight

5. Provide a crew escape capability

6. Automate aborts and abort determination

7. Provide the crew situation awareness

8. Test the flight hardware

9. Verify the flight software for all expected flight environments

10. Maintain a strong commit-to flight process

11. Explain all flight anomalies

12. Train for the unexpected

13. Provide sufficient ground support for flight status, abort confirmation and replanning

14. Improve planning tools with flight data

15. Update abort capabilities and perform necessary verification for all changes

16. Provide provisions for modular updates for new capabilities

\section{Conclusions}

In conclusion, the abort capabilities evolved throughout the life of the Space Shuttle program as changes occurred. There was a lot of learning as we went along; in hindsight more planning for upgrades and for automation would have helped keep systems more current. The shuttle abort capabilities were significantly improved along with added vehicle certification for the planned aborts. More importantly, improvements in training, crew procedures, situation awareness, and mission rules all led to much safer flights. Crew safety and a safe Orbiter return were maximized for the loss of a single main engine and crew survivability was significantly improved for multiple engine failures.

\section{References:}

1. NSTS-08209 Volume I, Shuttle Performance Assessment Document

2. NSTS-08290 Volume III, Systems and Environmental Dispersions

3. NSTS-08290 Volume IV, Generic Ascent Flight Design Requirements

4. NSTS-08347 Rev. C, Space Shuttle Contingency Aborts Data Book 


\section{Biographies}

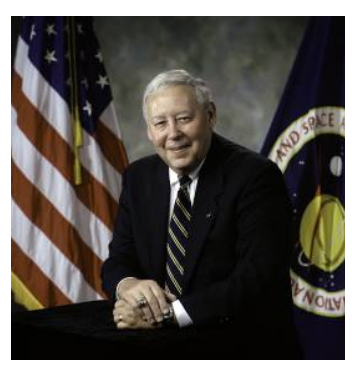

Edward M. Henderson, Mack has 50 years experience with NASA in a wide variety of jobs. After his cooperative education program with the Army at Redstone Arsenal, AL, working on rocket guided missiles. Mack transferred to the NASA's MSFC, where he worked in the Aeroballistics Lab helping to define the aerodynamics used for the Saturn V. After receiving a B. S. in Aerospace Engineering at Virginia Polytechnic Institute and State University, Mack went to the Manned Spacecraft Center in Houston, Texas and worked in Mission Planning and Analysis for Gemini, Apollo and Space Shuttle programs. He was the abort subsystem design manager for the shuttle and as a Flight Design Manager, Mack lead the shuttle design work for the first Spacelab mission and the first west coast launch (which never flew). He later headed the ascent and entry flight design, owning more than 1700 software I-loads used for shuttle ascent and launch aborts.

Mack moved to the Flight Directors Office, where he was responsible for Space Shuttle and the International Space Station Program integration for the mission operations and managed the SPAN (mission control's spacecraft analysis room) for more than 50 shuttle flights. Mack moved to the Shuttle Program (SSP) Office in 1990. While in the SSP, he helped set up the Space Shuttle Development office and control board that over saw major shuttle upgrade projects, designed to keep the shuttle flying to 2020. Mr. Henderson led a technical team on improvements for shuttle derived launch vehicles, significantly increasing performance at reduced cost. Once the vision for space exploration and the early retirement of the shuttle was announced, Mack helped set up the transition team charged with safely retiring the space shuttle. He led a team of project leads in an evaluation of costs and impacts for flying the Space Shuttle longer. Currently as the lead for advanced planning for shuttle applications that would help reduce risks and operations cost for future programs, Mack is the co-lead for a joint NASA and DoD team working on defining a space based solar power demonstration that could be flown up on the shuttle to the ISS for the first WPT from space.

Mr. Henderson has received some prestigious awards that include:

- 1983 NASA Exceptional Service Medal for his flight design leadership for the first Space Shuttle/Spacelab mission STS-9.

- 2001 AIAA Aerospace Maintenance Award for his work on the Space Shuttle upgrades

- 2007 NASA Exceptional Service Medal for his continued pursuit of improvements for shuttle flight safety

- 2010 AIAA Associate Fellow and Rotary National Award for Space Achievement 


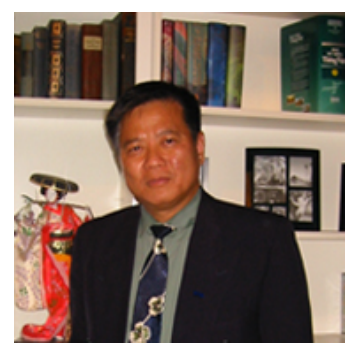

Tri X. Nguyen has had numerous opportunities that both challenged and helped to refine his managerial and leadership capabilities throughout a 32-year career in private industry and at NASA. Upon graduating from University of Missouri-Rolla in 1979, he began his career with McDonnell Douglas Astronautics Company in Houston as a structural engineer. Tri's first assignment was on the Orbiter Structural Certification and Flight Verification (STS-1 thru STS-6) Project. In 1983, he became a member of the Flight Mechanics Department. His duties included developing Shuttle capabilities for the Return to Landing Site, Terminal Area Energy Management, and Approach/Landing. In 1986, the Rockwell Space Operations Company recruited Tri to be their lead for the Descent Flight Design and Analysis Group. In 1988, he was hired by NASA to work in the Space Shuttle Program (SSP) Office as a Senior Systems Engineer. In this position, Tri was responsible for certifying the Intact Aborts (1 of 3 SSME out during ascent) and SRB/ET/Orbiter separation performances of each Space Shuttle flight (STS-26A thru STS-60) as well as managing development projects to improve the capabilities and safety of the Space Shuttle.

In 1993, he was selected as Manager of the Launch Package Phase 1 Office in the ISS Program. In this role, he was the key architect to formulate and implement the ISS Phase 1 Risk Mitigation Program. Responsibilities included formulation of the staffing requirements, management of the development of the ISS risk mitigation payloads, and negotiation with senior management teams of the Space Shuttle and Russian Space Station (Mir) Programs for payload flight manifest. All payloads were successfully demonstrated on the Space Shuttle and Mir test platforms and the objectives of the program were met. In 1997, he was assigned as Technology Program Integration Lead in the Exploration Office, where he formulated an integrated technology plan and served as the Agency Manager for the "Atmospheric and In-Space Systems" Thrust Area of the Cross Enterprise Technology Development Program for the NASA Headquarters (HQ) Space Science Office. In 2000, he was assigned to the NASA HQ SSP Office. In this role, Tri served as a technical liaison between the HQ SSP Office and JSC Offices.

After returning from NASA HQ in 2001, Mr. Nguyen was named the Manager of the Advanced Technology Development Office. Responsibilities included formulating the technology needs/roadmaps for the Human Exploration and Development of Space Enterprise and managing JSC technology development activities for the Next Generation Launch Technology Program. In addition to the Office Manager's responsibilities, he also accepted and performed various special assignments during this tenure. For example, In September 2001, he led the JSC expert team to develop technology requirements and solicitation materials, to review and prioritize the in-house technology development projects for NASA Unique Systems of the Space Launch Initiative. In October 2003, Tri was asked to be an executive officer for the Shuttle Service Life Extension Program (SLEP) Strategy Panel. He worked with the Chairman to form a team and coordinate all activities in support of the Shuttle SLEP II Summit in Galveston, Texas. The strategic mission models were successfully presented at the Summit on Feb. 17-18, 2004. In 2006, he was assigned to the Program Engineering Integration Office as a Systems Integration Lead to support the Constellation Analysis Working Group and the Shuttle Derived Heavy-lift Launch Vehicle Assessment Team. The results of the assessment were documented in NSTS 60583. Currently Mr. Nguyen is the NASA/JSC Lead to coordinate and support the AFRL Reusable Rocket-back System Return to Launch Site Flight Demo (Path-Finder Program) at Wright Paterson AFB. I also serve as deputy lead for Technology Applications and Assessments Team.

Earned a Bachelor of Science in Aerospace Engineering from University of Missouri-Rolla - 1979, a Master of Mechanical Engineering from University of Houston - 1982, and a Master of Science in Mathematics from University of Houston-Clear Lake - 1986. Attended OPM's Executive Development Seminar, Parametric Cost Estimating, Project Risk Management, Systems Engineering, and Managing Influence Process Seminars; Developing People and Human Resource Management Seminars, Seminar in Management, and Project Management Seminars. Received the Silver Snoopy Award, STS-44 Manned Flight Awareness Award, JSC Certificate of Commendation (twice), Superior Accomplishment Awards, NASA/Russian Space Agency Phase 1 Achievement Award, and Letters of Appreciation from the Director of the Glenn Research Center and the Deputy Associate Administrator. 